\title{
Advancing practical applications of resilience in Aotearoa-New Zealand
}

\author{
David Wither $^{1}, \underline{\text { Caroline Orchiston }}^{1}$, Nicholas A. Cradock-Henry $^{2}{ }^{2}$ and Etienne Nel ${ }^{3}$
}

\begin{abstract}
Resilience is increasingly used to inform natural hazard risk management. From global to national to local levels of governance and decision making, resilience concepts are becoming institutionalized and operationalized in both public and private domains. However, as these ideas have shifted from their origins in ecology and been adopted by other disciplines, policy makers, and practitioners, key insights from the initial ecological conceptualization have been left behind. The resulting gap between resilience as originally theorized and its current implementation gives rise to several interconnected challenges: (i) loss of nuance in the meaning of the concept due to rapid adoption, which leads to: (ii) an inability to adequately account for normative or qualitative aspects of social theory, and: (iii) the problem of measurement. Key factors associated with resilience are intangible (difficult to objectively measure) and public bureaucracies are reliant upon objective measurement, i.e., targets and indicators, to operationalize policies. Multi-capital frameworks have been advanced as a potential solution to the problem of measurement in the literature. In this paper, we critically analyze how the concepts of social and human capital can be used to address these challenges and account for intangible sources of value. Drawing on a case study of complex multi-hazards in rural Aotearoa-New Zealand (NZ), as well as the NZ government's Living Standards Framework (a multi-capital framework) we highlight the importance of addressing these challenges to adequately realize the benefits of resilience and identify the successes and limitations of this approach. Results provide insight into the interlinked nature of the challenges and the importance of reconciling resilience theory and praxis. Findings also demonstrate the potential ways in which a combination of resilience thinking and multi-capital frameworks can add value to decision-making structures within public bureaucracies, the private sector, and academia.
\end{abstract}

Key Words: disaster management; indicators; livelihoods; measurement; metrics; multi-capital; rural; monitoring and evaluation; socialecological systems; well-being

\section{INTRODUCTION}

Around the world, losses from natural hazard events continue to rise, accelerating research and policy initiatives aimed at enhancing resilience and reducing risk and vulnerability (Cutter et al. 2015). Synergies between international policy frameworks, including between the United Nations' Framework Convention on Climate Change (UNFCC), the Sustainable Development Goals, and the Sendai Framework for Disaster Risk Reduction, are being realized to take advantage of the Agenda 2030 policy window (Kelman et al. 2015, Bowen et al. 2017). As a result, reducing vulnerability and building resilience are no longer seen as competing, but rather as parallel concepts, converging toward the improvement of societal outcomes (Cannon and MüllerMahn 2010, Miller et al. 2010, Turner 2010, Lei et al. 2014, Connelly et al. 2017).

In the international literature, resilience concepts have become central to framing, interpreting, and analyzing the dynamics of change for people and of places as part of integrated complex adaptive systems (Adger et al. 2005, Aldunce et al. 2015). Related to this, social-ecological resilience has been applied in diverse contexts, and has generated a growing body of empirical, conceptual, and methodological literature (Marshall et al. 2007, Manyena et al. 2011, Kates et al. 2012, Cradock-Henry et al. 2018). A parallel strand in psychology (Alexander 2013) has also delivered valuable insights into the social dimension of resilience that have become increasingly recognized for their relevance (Ungar 2008, 2011, 2018, Berkes and Ross 2013).

Resilience concepts are also widely employed in policy, guiding efforts toward achieving global sustainability as part of the wider development agenda (Hajer et al. 2015, Ocampo and GómezArteaga 2016). The Sendai Framework for Disaster Risk
Reduction, for example, provides a focal point for governments to align efforts on disaster risk reduction (UNISDR 2015), and has accelerated research to address the social, economic, and environmental conditions that preconfigure disaster (Kelman et al. 2015). The new emphasis on resilience, and its inclusion within the Sendai and other high level strategy documents and international initiatives has prompted critical reflection from practitioners, policy makers, and academics on the significance (Pimm et al. 2019), value (Salomon et al. 2019), and practical application of resilience concepts (Liu 2014, Bronen 2015, Cradock-Henry et al. 2019).

Resilience is a proven boundary concept (Baggio et al. 2015), bringing together diverse and disparate disciplines, reconciling theory, policy, and practice (Brown and Westaway 2011, Manyena et al. 2011). It is not, however, without its critics (Brown 2014, Olsson et al. 2015). As resilience becomes more widely applied in policy and practice, the need for critical reflection on its relevance for addressing social questions relating to justice, equity, and power (Bahadur and Tanner 2014, Cretney and Bond 2014, Taubenböck and Geiß 2014) has become more pronounced. Within this transition, nuance, normative questions, and practical problems with measurement arise, that need to be acknowledged and accounted for in order to fully realize its potential value in both policy and practice (Hayward 2013, Cretney and Bond 2014, Brown 2014). Building on this, we critically analyze the ways in which resilience has been applied, based on case study analysis of recent rural disasters in Aotearoa-New Zealand (NZ).

\section{RESILIENCE THINKING}

The etymological origins of resilience can be traced back centuries (Cote and Nightingale 2012, Alexander 2013), with core concepts emerging in ecology, psychology, and later in natural hazards

${ }^{1}$ Centre for Sustainability, University of Otago, ${ }^{2}$ Landscape Policy \& Governance, Manaaki Whenua - Landcare Research, ${ }^{3}$ School of Geography, University of Otago 
research (Brown 2014). In the 1970s, ecology was dominated by natural equilibrium theory (Holling 1973, 2001, Berkes and Folke 2000). In 1973, C.S. "Buzz" Holling introduced a revolutionary rejoinder. Rather than viewing nature as having a single stable state to which it always returns following disturbances, Holling (1973) posited a world of multiple stable states with fundamentally different characteristics and thresholds between them. Resilience, in Holling's view, represented the ability of an ecological system to absorb or bounce back from a disturbance without changing its essential characteristics. It was about maintaining a preferred stable state without flipping to an undesirable one as a result of outside influence.

Natural equilibrium theory was grounded in established quantitative methods such as conceptual and mathematical models, computational simulations, and advanced data analysis. However, in order to consider multiple stable states, as Holling (1973) theorized, it was necessary to consider more abstract, and qualitative characteristics that might influence the long-term persistence of relationships (Holling 1973). Shifting attention to the tensions between efficiency and persistence, constancy and change, and predictability and unpredictability (Table 1; Alexander 2013) introduced a new qualitative emphasis to resilience, resulting in two contrasting approaches (Holling 1996): engineering resilience and social-ecological systems (SES) resilience. Holling (1973:1) explains the distinction in the following terms:

Table 1. Tensions between engineering resilience and socialecological interpretations of resilience (adapted after Holling 1996).

\begin{tabular}{ll}
\hline \hline Engineering resilience & Social-ecological resilience \\
\hline Efficiency & Persistence \\
Constancy & Change \\
Predictability & Unpredictability \\
Certainty & Uncertainty \\
Fail-safe & Safe-fail \\
\hline
\end{tabular}

If we are examining a particular device designed by the engineer to perform specific tasks under a rather narrow range of predictable external conditions, we are likely to be more concerned with consistent non variable performance in which slight departures from the performance goal are immediately counteracted. A quantitative view of the behavior of the system is, therefore, essential... But if we are dealing with a system profoundly affected by changes external to it, and continually confronted by the unexpected, the constancy of its behavior becomes less important than the persistence of the relationships. Attention shifts, therefore, to the qualitative and to questions of existence or not. [emphasis added]

These two fundamental paradigm shifts, and the distinctions they entail, are important. Although resilience thinking was adapted from ecology and taken up within the social and behavioral sciences, policy, and practice, this emphasis on qualitative analysis and multiple stable states was not. In this paper, we argue this absence has resulted in negative outcomes with respect to understanding responses to adverse events. Furthermore, by reincorporating these ideas into resilience thinking, as per the Sendai Framework, significant conceptual and methodological progress can be made. As will be discussed below, multi-capital frameworks, such as the Living Standards Framework, hold significant potential for aiding the systemic integration of qualitative analysis into institutional decision-making frameworks.

Although early work on resilience focused exclusively on natural ecological systems, parallel developments were also underway in psychology. Both of these streams of resilience thinking would later influence debates and guide empirical research in the social sciences more broadly (Cote and Nightingale 2012, Alexander 2013). In psychology, the aim was to better understand the characteristics of individuals that enabled them to cope with external shocks (Garmezy et al. 1984). Subsequent findings from this field have highlighted the significance of community dynamics, well-being, participation, and engagement (Paton and Johnston 2001), links between well-being and resilience (Ungar 2018), and the negative association between excessive stress and cognitive functioning (Shields et al. 2016). Many of these developments, including their quantitative orientation (Ostadtaghizadeh et al. 2015), were also subsequently incorporated into socialecological interpretations of resilience.

The terminology and metrics of resilience have also increasingly been used in disaster risk management to understand and manage the impacts and implications of natural hazards, and to draw attention to social, economic, and cultural conditions that influence disaster-related outcomes locally, nationally, and globally (Kelman et al. 2015, Aitsi-Selmi et al. 2016, Zaidi 2018). The Sendai Framework for Disaster Risk Reduction is the most influential and visible of these policy instruments, a 15-year voluntary non-binding agreement signed by $187 \mathrm{UN}$ member states (UNISDR 2015). The stated aim of the framework is "the substantial reduction of disaster risk and losses in lives, livelihoods and health and in the economic, physical, social, cultural and environmental assets of persons, businesses, communities and countries" (UNISDR 2015:12). Employing resilience concepts throughout, the framework explicitly links reducing losses and minimizing harm with the need to address underlying social conditions, and includes targets, indicators, and legislative instruments to guide implementation. The framework also emphasizes shared responsibility for disaster risk reduction, and the roles local and national governments, the private sector, and other stakeholders can play to promote collective action (Aitsi-Selmi et al. 2015).

\section{Challenges for resilience application, interpretation, and operationalization}

Resilience concepts provide a set of powerful tools and concepts to analyze the dynamic interactions between human activity and the natural environment. However, the practical application of resilience to social issues differs markedly from Holling's (1973) initial conceptualization. The resulting dissonance between resilience in theory and in practice, gives rise to several interconnected challenges: (i) loss of nuance in the meaning of the concept due to rapid adoption, (ii) an inability to adequately address the normative aspects of social theory, and (iii) difficulties encountered when seeking to integrate resilience thinking into public bureaucracy due to the major challenges associated with measuring critical factors. 
First, resilience has been rapidly (and in some cases) uncritically mainstreamed into policy. For example, resilience in the Sendai Framework is defined as:

\begin{abstract}
The ability of a system, community or society exposed to hazards to resist, absorb, accommodate to and recover from the effects of a hazard in a timely and efficient manner, including through the preservation and restoration of its essential basic structures and functions (UNISDR 2015:9).
\end{abstract}

Although this definition of resilience is becoming normalized, it overlooks the tension between the capacity (or desirability) of "bouncing back" to a pre-disaster state, compared to transformative and adaptive pathways, "bouncing forward" and "bouncing back better" (Walker et al. 2006, Folke 2016, Brundiers and Eakin 2018). It also contains no mention of Holling's (1973) paradigm shift, which draws attention to the qualitative as well as the quantitative. Holling's $(1973,1996)$ distinction between engineering and SES resilience is especially relevant for disaster risk reduction. Although engineering resilience is useful in contexts requiring efficiency, constancy, certainty, and predictability, their opposites, persistence, uncertainty, unpredictability, and change (Table 1), are far more relevant to disaster risk reduction, a field constantly confronted by uncertainty and the unexpected (Hewitt 2013, Sword-Daniels et al. 2016).

Holling's (1973:1) observation that this "orientation may simply reflect an analytic approach developed in one area because it was useful and then transferred to another where it may not be," highlights the problem. In that context, Holling was referring to how scientific methods in physics had influenced the development of natural equilibrium theory in ecology. However, due to differing fundamental assumptions about external conditions (predictable vs unpredictable, constancy vs change, etc.), applying ideas from physics to ecosystems was ill-founded. A similar argument can be made for disaster risk reduction. Because policy makers, practitioners, and academics are frequently confronted with the unexpected and have very little certainty, it may be more effective to focus on the long-term persistence of relationships rather than their efficiency. Yet this nuance and the complexity surrounding resilience thinking has been lost in the simplified definitions that are rapidly becoming embedded in policy and practice, which in turn leads to a quantitative orientation for implementation. For resilience thinking to be an effective antidote to negative outcomes of disaster, it is important to recognize all that this paradigm shift entails and systematically incorporate qualitative analysis into the institutional decision-making processes.

The second challenge for incorporating resilience into policy is its limited conceptualization of the normative dimensions of social theory such as structure, power, and agency (Cote and Nightingale 2012, Olsson et al. 2015, Tanner et al. 2015, CalderónContreras and White 2020). Again, the definition of resilience used in the Sendai Framework reveals problematic aspects of transferring ecological concepts to social-systems more generally (Cote and Nightingale 2012, Brown 2014, Cretney and Bond 2014, Tanner et al. 2015). Although early SES literature did consider the effectiveness of different governance arrangements (Adger et al. 2005), often in the context of managing common pool resources, there was little accounting for the social processes that shaped and influenced local conditions. Walker et al. (2006), for example, acknowledged that some systems may only be desirable for a subset of the population and undesirable for another, but did not examine the social inequalities, rights, or power relations that shaped it.

This challenge can also be referred back to the quantitative focus inherent in practical implementation. The normative dimensions of resilience primarily come from a qualitative perspective, yet the way in which resilience thinking has been operationalized precludes their incorporation. In response to these criticisms, there is evidence for a qualitative turn in resilience thinking (Brown 2014), and greater attention being accorded to not just what we do, but how and who (Kaika 2017). Emphasis is now being placed upon co-creating resilience solutions, and on public participation in the disaster recovery processes, including academic research in post-disaster contexts. Research is becoming less something that is done for people and instead being done with people (Vallance 2015, Kwok et al. 2016, Kaika 2017, CradockHenry et al. 2019). As the Sendai Framework states, shared engagement amongst all stakeholders is vital (UNISDR 2015).

Finally, a third challenge for resilience in policy and practice is measurement (Carpenter et al. 2001, Arbon et al. 2016, Kaika 2017, Pimm et al. 2019, Salomon et al. 2019). Although resilience thinking in the face of climate change and other disruptive hazard events may be an appealing notion, it is difficult to integrate into existing governance mechanisms (Dovers and Hezri 2010, Nalau and Handmer 2015, Adger et al. 2018). The primary mechanisms used by public bureaucracies to demonstrate accountability or good decision making is to require quantifiable results of interventions and investments. This approach requires measurable indicators (Hallegatte and Engle 2019) and this often fails to account for intangibles such as trust or sense of community (Cutter et al. 2014).

Various resilience metrics have been advanced in the literature (see Ostadtaghizadeh et al. 2015 for a review). In NZ, for example, Kwok et al. (2016) proposed a suite of social resilience indicators developed from interviews with academics, policy makers, and practitioners (Table 2). Even though the framework, divided into structural and cognitive indicators, was co-designed with research participants comprising academics, policy makers, and practitioners who worked in the field, it fails to reconcile the tension between readily quantifiable structural (objective) and cognitive (subjective) indicators. As noted by Stiglitz et al. (2018:13), this presents a fundamental problem: "What we measure affects what we do. If we measure the wrong thing, we will do the wrong thing. If we don't measure something, it becomes neglected, as if the problem didn't exist." Goodhart's law (Goodhart 1975) is equally relevant: "When a metric becomes a target, it ceases being a good metric" (Strathern 1997).

At the supra-national scale then, universally quantifiable indicators for resilience tend to be imperfect because of their complexity and uncertainty (Hallegatte and Engle 2019), doubly so for subjective measures such as trust or sense of community (Berkes and Ross 2013). Although there are scales to measure these concepts, interpretation and attribution is extremely complex, contextual, and not readily transferrable (Scrivens and Smith 2013). Proxy indicators provide an imperfect solution, but these can lead to significant pitfalls and perverse incentives 
(Carpenter et al. 2001, Birkmann 2007, Dakos et al. 2015). Cocreating process-based indicators of intangible phenomena could provide a partial solution (Hallegatte and Engle 2019). For example, a priori development of quantitative indicators for trust could be built into the policy design phase to ensure it is adequately accounted for, rather than during ex-post outcome evaluations. The impacts and implications of disruptive events cannot be reduced to key metrics that might be transferable across multiple domains and contexts (Cutter et al. 2014). However, despite these constraints, the general process by which good outcomes are generated, such as through good policy design and implementation, is transferable.

Table 2. Social resilience indicators (adapted after Kwok et al. 2016)

\begin{tabular}{ll}
\hline \hline Structural Indicators & Cognitive Indicators \\
\hline Educational attainment & Outcome expectancy \\
Pre-retirement age & Action coping/self-efficacy \\
Transportation access & Critical awareness \\
Communication capacity & Responsibility \\
(English) Language competency & Trust \\
Food provisioning capacity & Place attachment \\
Non-special needs & Sense of community \\
Health insurance coverage & Community participation \\
Health care capacity & Empowerment \\
\hline
\end{tabular}

In light of these challenges, multi-capital frameworks have been proposed as a potential pathway to better account for both the quantitative and qualitative dimensions of resilience, and provide a link between research, policy, and practice (Ostadtaghizadeh et al. 2015).

\section{Multi-capital frameworks and disaster risk and resilience in Aotearoa-New Zealand (NZ)}

$\mathrm{NZ}$ is a small, developed economy exposed to low-frequency, high-magnitude events such as earthquakes, volcanic eruptions and tsunami; as well as more frequent damaging hydrological and climatic events. The country is seismically active, situated on the boundary of two tectonic plates, and has had several damaging earthquakes over the last decade including the 2010/2011 Christchurch and Canterbury earthquakes and the 2016 Kaikōura earthquake (Potter et al. 2015, Stevenson et al. 2017).

In recent years, resilience concepts have begun to be applied more widely in NZ policy and practice, first, through the Living Standards Framework (LSF) and second, the National Disaster Resilience Strategy (NDRS). The LSF is a multi-capital framework developed by the NZ Treasury. Multi-capital frameworks originated in international development (Morse and McNamara 2013) and use economic concepts of wealth creation, value, or "capital" (e.g. financial, social, environmental, human) to better understand livelihoods. The LSF provides a conceptual, theoretical, and practical basis for thinking about good economic, environmental, and social policy in an integrated way; policy that aims to enhance individual and communal well-being on a sustained basis (Karacaoglu 2015).

The framework is flexible, and can focus attention on policy impacts across different dimensions of well-being, as well as on long-term and distributional issues and implications. The framework takes into account 12 domains of current well-being outcomes, the four capital stocks that support well-being now and into the future; and risk and resilience (Fig. 1). The LSF is designed to be internationally and intertemporally comparable, suitable for developed countries, and also accounts for that which is uniquely important to NZers (NZ Treasury 2018).

The second development is the adoption of the LSF as part of NZ's new National Disaster Resilience Strategy (Ministry of Civil Defence \& Emergency Management 2019). The NDRS outlines the vision and long-term goals for Civil Defence and Emergency Management, and the objectives to be pursued to meet these goals. It provides the strategic direction and vision for objectives and priorities to increase NZ's resilience to disasters. The NDRS “is intended to provide a common agenda for resilience that individual organisations, agencies, and groups can align with for collective impact" (Ministry of Civil Defence \& Emergency Management 2019:10). To operationalize this vision, the NDRS uses the Living Standards Framework (LSF) to advance its wholeof-government well-being and resilience agenda. In the foreword, then-Minister of Civil Defence and Emergency Management Hon Kris Faafoi emphasizes this by stating that "The Strategy has a strong focus on wellbeing. It incorporates the Treasury's LSF and considers the types of resilience needed to protect and grow our wellbeing" (Ministry of Civil Defence \& Emergency Management 2019:1). Furthermore, the NZ government's obligations to the Sendai Framework, and therefore its approach to resilience, is explicitly linked to this framework through the NDRS and a series of technical papers discussing the LSF (NZ Treasury 2018) in relation to risk and resilience (Frieling and Warren 2018), social capital (Frieling 2018), and human capital (Morrissey 2018) among others.

Compared to resilience thinking, a multi-capital approach places a greater emphasis on the different needs of different people, which allows for context and normative factors such as structure, agency, empowerment, and trust to be incorporated into the analysis (Tanner et al. 2015). Although multi-capital frameworks, such as Sustainable Livelihoods (Bebbington 1999, Mikulcak et al. 2015), show potential in combination with resilience theory, these links have not yet been widely explored (Tanner et el. 2015, Zhao et al. 2019).

To illustrate this, case studies from rural NZ are now discussed. Empirical evidence is used to show how multi-capital frameworks can be used to illuminate intangible phenomena and incorporate them into decision-making processes.

Two capitals, human and social, provide the basis for discussion. Human capital refers to people's physical and mental health, as well as their skills and knowledge (Morse and McNamara 2013). Social capital is more nuanced and can be seen as a resource, an input, or as an outcome (such as of certain types of policy settings). Furthermore, there is often a distinction made between bonding, bridging, and linking types of social capital (Putnam 2000, Woolcock 2001, Field 2016). Bonding social capital refers to the ties that bind people, such as immediate family or friends. Bridging social capital is more distanced, such as those people you work with, acquaintances, or the wider community. Linking social capital refers to relationships with those who are outside of the wider community, which can enable access to a wider range of resources (Woolcock 2001). These relationships often involve 

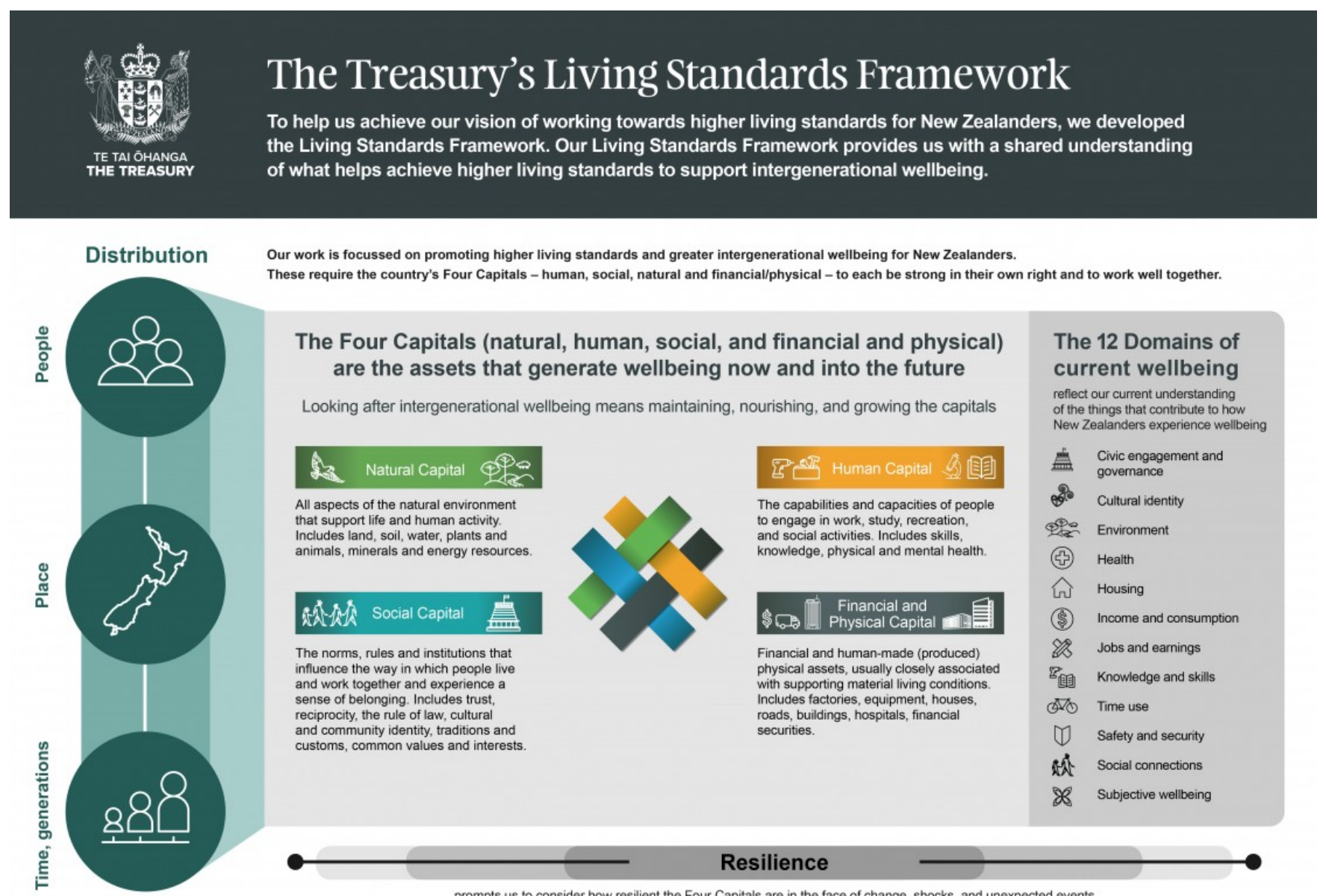

Our work is focussed on promoting higher living standards and greater intergenerational wellbeing for New Zealanders.

These require the country's Four Capitals - human, social, natural and financial/physical - to each be strong in their own right and to work well together.

The Four Capitals (natural, human, social, and financial and physical) are the assets that generate wellbeing now and into the future

Looking after intergenerational wellbeing means maintaining, nourishing, and growing the capitals

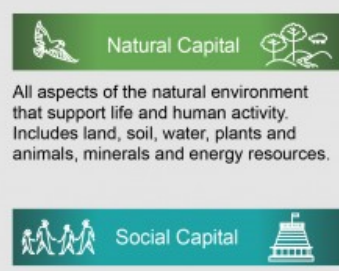

The norms, rules and institutions that influence the way in which people live and work together and experience a
sense of belonging. Includes trust. reciprocity, the rule of law, cultural and community identity, traditions and customs, common values and interests.
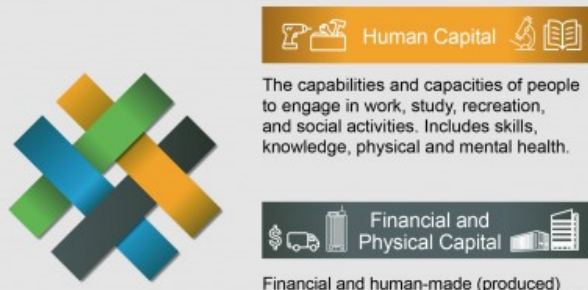

The capabilities and capacities of people and social activities. Includes skills,

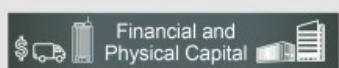

Financial and human-made (produced) physical assets, usually closely associated whysical assets, usually closely associated Includes factories, equipment, houses,
roads, buildings, hospitals, financial reads, building. to engage in work, study, recreation,
The 12 Domains of current wellbeing reflect our current understanding of the things that contribute to how New Zealanders experience wellbeing

点 Civic engagement and

governance

Cultural identity

QPe Environment

(5) Heath

जิ Housing

(5) Income and consumption

18 Jobs and earnings

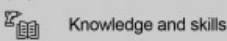

(ब) Time use

(1) Safety and security

Social connections

Subjective wellbeing

Resilience

prompts us to consider how resilient the Four Capitals are in the face of change, shocks, and unexpected events

people in dissimilar situations. The linking and bridging varieties of social capital are mainly present in the results, which can have significant impacts on outcomes for adverse events (Aldrich 2012, Cradock-Henry et al. 2019). Another key point in the literature is that social capital is not always regarded as positive. Referred to as social capital's "dark side," strong group ties, such as described in the bonding variety, can in some instances lead to negative outcomes for groups (Durlauf 1999). For more detailed discussions on social capital in the disaster risk reduction context, see Aryal and Wilkinson (2019) and Kwok et al. (2019). Finally, it is important to note that we use the concept of social capital in an exploratory way, to gain insight into the dynamics of individual response capabilities and resilience, following a disaster. Although metrics for social capital have been proposed, the issues of attribution that plague resilience are equally prevalent here, and so the aim is not to "measure" social capital but to describe it (Harper 2002, Halpern 2005, Scrivens and Smith 2013, Field 2016).

\section{METHODS}

Well-being concepts are central to both the NDRS and the LSF (Ministry of Civil Defence \& Emergency Management 2019, NZ Treasury 2019). To illustrate this multi-capital approach to resilience and its implications for policy and practice, we discuss three case examples of disruptive events, to demonstrate how a policy response to an event can have a positive or negative impact on social and/or human capital, which is then reflected back to the dissonance between resilience as conceptualized versus operationalized. Each involves an event, a reaction, and a reflection by key stakeholders on the effectiveness of that reaction. The LSF multi-capital framework, alongside resilience thinking, is used to structure the results and discussion (Fig. 1).

\section{Study area and context}

Aotearoa-New Zealand provides a rich empirical context for the study of resilience and its incorporation into policy and practice. Agriculture is a key contributor to national and regional economies in the country. Geo-climatic hazards are common, with adverse implications for rural regions, disrupting farming practices, through animal mortality and infrastructure damage (Spector et al. 2019).

The case studies focus on the South Island's Hurunui District (Fig. 2). Encompassing an area of $8646 \mathrm{~km}^{2}$, it is due north of the Island's main urban center, Christchurch. With a population of approximately 12,000 people, the local economy is primarily 
made up of agribusiness (dairy, sheep, and beef farming), forestry, and tourism. The area was deliberately chosen because of its exposure to multiple adverse events in recent years (Fig. 3), including earthquakes and an extensive drought (2014-2017). In 2017, Mycoplasma bovis ( M. bovis), a bacterial disease affecting dairy and beef cattle, resulted in a major biosecurity hazard and response.

Fig. 2. Study area location (Google Maps/https://visithurunui. co.nz/ 2019).

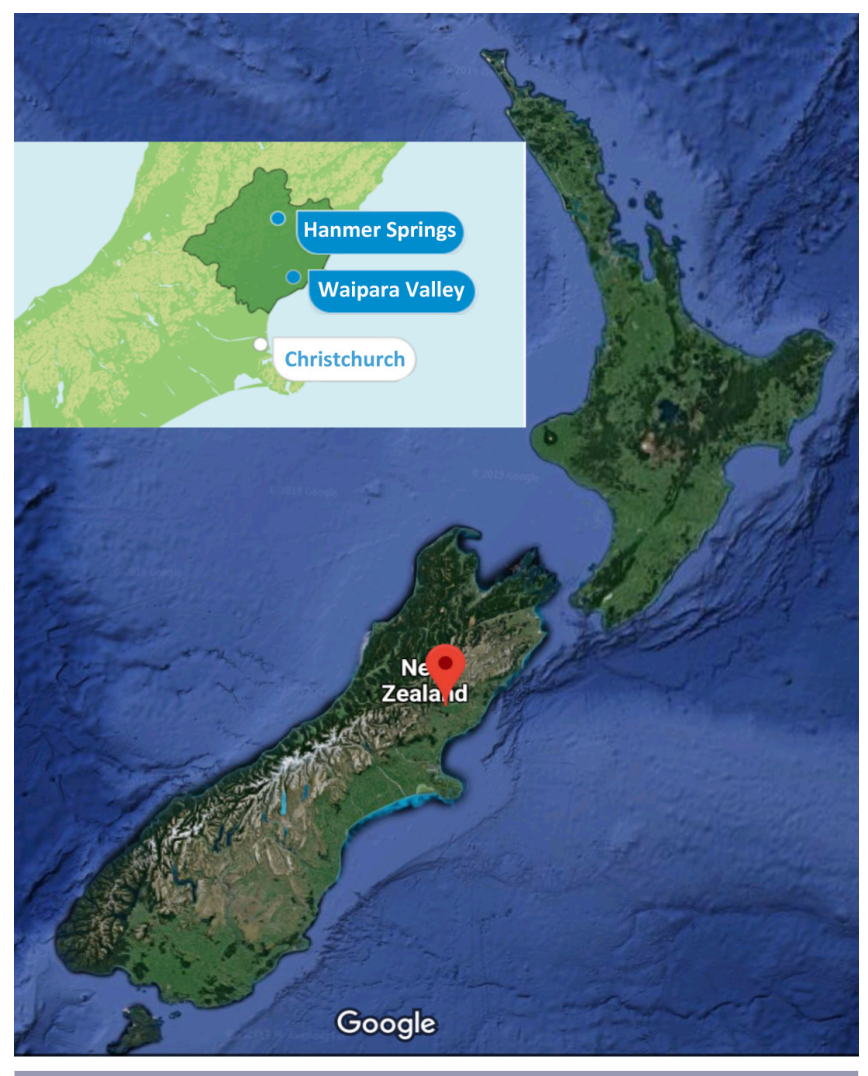

Fig. 3. Time line of major events in the Hurunui District.

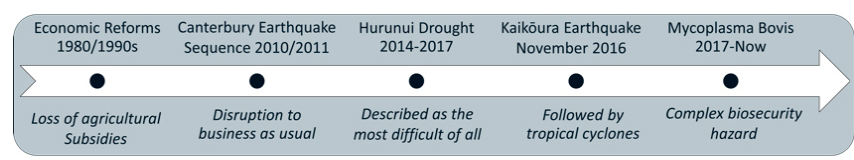

In addition to physical hazards, structural changes and the legacy effects of economic restructuring over the last 30 years have had a considerable impact on agricultural practices and rural communities in NZ. In 1984, nearly $40 \%$ of the average income of NZ's sheep and beef farmers came from government subsidies (Burton and Peoples 2014). Within 12 months this was reduced to almost zero (Federated Farmers 2001). As described by Kelsey (1995:11): "The mission of NZ's change agents [was] to initiate and entrench the 'right' policies, not to secure socially acceptable outcomes. According to their theories, the two would ultimately coincide." These were ideological, neoliberal free market policies with key changes for farmers including the removal of all agricultural subsidies, removal of minimum price schemes on wool, beef, dairy, and sheep products, reduced tariffs, and deregulated finance markets (Kelsey 1995). Throughout the 1980s and 1990s, neoliberal reforms led to the privatization of rural extension and consultancy services that had previously been provided at no cost (Cloke 1996). The restructuring of the economy during this time followed a financial crisis, ushering in an emphasis in NZ on evidence-based policy making.

International analyses often consider these reforms to be broadly positive (e.g., Vitalis 2007), however local experiences were markedly different. What remains beyond question is that significant changes across NZ's agricultural system exposed farmers to market forces in a way in which they never had been before. Today, a lack of effective environmental regulation combined with significant intensification has led to complex social, economic, and environmental issues that must now be addressed (Barnett and Pauling 2005, Jay 2007, Gray and Le Heron 2010), and are reflected in perceived stressors, farmers' responses, and capacities through time.

\section{Data collection and analysis}

The relatively small size of the NZ science and policy communities provides unique opportunities for greater interaction and insight into the ways in which academic concepts are operationalized in local, regional, and national decision-making processes for disaster risk reduction. Qualitative methods were used to gain insight into the effectiveness of government responses to natural hazard events. These included in-depth, semi-structured interviews with stakeholders at multiple sites and levels, from local farmers to central government actors and decision makers. Interviews were supplemented with a focus group discussion comprising farmers and several elected local government representatives (who were also farmers). Secondary data included documentary analysis of local, regional, and national policy, and planning materials/strategy were also reviewed to help contextualize the research findings and delineate the social and ecological characteristics of the study area. The choice of research methods was informed by a close reading of similar studies elsewhere, which have relied on participatory and qualitative methods to obtain "thick information" about local conditions (Young et al. 2010, Naess 2013, Cradock-Henry et al 2018).

Research participants were identified using deliberate and snowball sampling methods. The general approach was characteristic of a social-ecological inventory (Cradock-Henry et al. 2019), where one or two key informants were identified at each level prior to data collection, and each participant was asked to provide a list of relevant people. Those whose names were mentioned frequently or emphasized by others were selected for interviews. Referrals to others were often across scales, for example, contact with one farmer participant led to contact with a regional expert, which then led to a central government official, which in turn led to a key informant at the highest levels of government. Many informants would not have been accessible through formal channels. Interviews were conducted between August 2018 and March 2019.

Semi-structured interviews $(n=47)$ and one focus group $(n=9)$ provided the majority of the data. Many focus group participants 
were subsequently interviewed on an individual basis. All interviewees had some experience with disruptive events in the Hurunui and were broadly categorized into three groups: (i) members of farm households; (ii) local and regional government and organization representatives (elected and unelected); and (iii) national government and organizational representatives (unelected). Many participants were part of more than one group, for example, local government representatives were often farmers as well. Some regional experts often played significant roles in central government decision-making processes. Participants were assigned to multiple groups in order to account for this, meaning that the total number of participants in Table 3 does not add up to the actual number of participants.

Table 3. Distribution of interviewees.

\begin{tabular}{lc}
\hline \hline Groups & Number of Participants \\
\hline Group 1: Farmer households & 20 (includes focus group) \\
Group 2: Local and regional government and & 28 \\
organizations & 23 \\
$\begin{array}{l}\text { Group 3: National government and } \\
\text { organizations }\end{array}$ & \\
\hline
\end{tabular}

Rather than a comparative analysis of experience at the local level, a vertical analysis with perspectives from all levels was undertaken. The focus group was made up of farmers, some of whom were also local government representatives, such as Winton Dalley, the Mayor of the Hurunui (who consented to be named). Careful attempts were made to interview women farmers in order to obtain a diversity of perspectives because gender has been highlighted as a significant factor in other research on rural issues (Davidson 2016).

Aotearoa-New Zealand is a bi-cultural nation, and during the planning process careful consideration was given to how to engage with Māori (the indigenous people of Aotearoa-New Zealand). The population of the district is predominantly NZ-European ( $p \bar{a} k e h \bar{a}, \sim 92 \%$ of the total population) and the focus was on indepth, vertical analysis to obtain insight into the specific issues associated with the three case examples. Because of time and resource constraints, there was no specific Māori engagement, but we acknowledge that in NZ, Māori have significant rural interests, commercial agribusiness, and forestry that may be exposed to a range of hazards. The gender distribution was 24 (40\%) women, and $35 \mathrm{men}(60 \%)$. Ethical approval was obtained, and attribution of specific results is limited to which group they belonged to ensure confidentiality.

Interviews were conducted in the Hurunui, Christchurch (the regional center), and Wellington (the capital city) in order to capture data from a range of key informants across a number of agencies. Data was inductively analyzed to identify key themes. The aim of this analysis was to gain insight into institutional and community responses to adverse events in Hurunui, and to understand the impacts on the social and human capital dimensions of SES resilience. Interviews with farm households were undertaken first for multiple reasons: (i) it allowed those impacted by the events to set the scene, (ii) to provide an initial understanding of the impacts and consequences of recent disruptive events from their perspective, and (iii) to identify the organizations and agencies, and key informants within those organizations and agencies who played a role in responding to events. Although all perspectives were important, there was an intention in advance to begin from the "bottom up" (Naess 2013). This approach was advantageous because the organizations and agencies that farm household participants saw as playing key roles differed from what was expected. Key themes identified from initial interviews were used to solicit information from local and national representatives to build an understanding of the major events from the perspectives of those who experienced it, those who responded to it, and those who organized the response.

\section{RESULTS}

Results from interviews and focus groups highlight the experiences of those impacted by earthquake, drought, and $M$. bovis; the institutional, organizational and community responses to them; and outcomes from the perspectives of those involved. Selected examples are used to illustrate how the LSF provides unique insights into response dynamics and how this can aid the operationalization of SES resilience.

\section{Coping with drought}

The first example to be discussed is the 2014-2017 Hurunui drought. Unusually for NZ, the drought persisted through two winters, making it one of the longest droughts in recent history (and the worst since 1998-1999), with significant impacts on spring grass growth. Local precipitation fell from an average of $200+\mathrm{mm}$ per year, to $60 \mathrm{~mm}$, grass growth slowed, and costs of supplemental feed rose dramatically because of increased demand. Because of feed shortages, farmers substantially reduced animal numbers, and in some instances completely destocked (Mol et al. 2017). For farmers, the drought created significant uncertainty about the future and affected farmer well-being because of the long-term nature of the stress. This stress was both personal and financial in nature, as one respondent noted: "It just does your head in. It really does... $90 \%$ of farmers love their stock, they really want to look after them." All farmers interviewed considered the drought to be the most challenging of the three events because of this long-term uncertainty. An independent survey conducted in April 2018 asking questions about recent hazard events including the drought and earthquake supports this view, with $30 \%$ of participants in the Hurunui stating they were still struggling to deal with the drought, compared to $15 \%$ of participants who were struggling in the aftermath of the earthquake (All Right? 2018, https://www.allright.org.nz/ uploads/images/090718TakingthePulseKaikouraHurunuiSUMMARY1. pdf).

The primary mechanism for responding to the drought was through the Ministry for Primary Industries' (MPI) Primary Sector Recovery Policy (2016), also known as the Adverse Events policy, which provides operational funding to Rural Support Trusts (RSTs) for farm-level assistance. The RSTs are a full-time, i.e., not just in times of crisis, national organization comprising retired farmers who volunteer their time to support farmers (as opposed to farming businesses) following adverse events. These organizations operate independently and there are 14 chapters nationwide.

From a government perspective, the RSTs are seen as one of the most effective and cost-efficient tools for post-event response and 
support. This research's scope covered the North Canterbury Chapter of the RST, and the results directly relate to it. MPI classified the drought as a medium scale event, triggering NZ\$400,000 for the local RST to use. Exemplifying a lack of social capital, regional and national level government representatives observed that farmers do not always trust the government, accordingly, their role in funding the RSTs is minimized at a local level. Local farmers were often unaware of the role the government played in supporting the RSTs work. RST representatives confirmed this. It should also be noted that the RSTs were heavily relied upon in the initial phases of the M. bovis response (discussed below), which led to significant tension towards MPI, because RSTs felt their efforts were underresourced and largely unrecognized. This was described as a significant risk to their relationship by both parties.

Locally, the RST's efforts were widely lauded by all farming participants, from the most progressive, to the most conservative. In response to a question on whether the government had a role in responding to such climate events, one particularly staunch farmer stated "Nah it's just Mother Nature being a bitch really. In all honesty, it's our problem." The next question discussed the impact of the RSTs, where he said: "they're lovely people, very thoughtful, and by doing what they do ... having someone just turn up and have a yarn to you ... it's worth gold. It really is." $\mathrm{He}$ was unaware of the role the government played in supporting the organization. The organization ascribes this success to strong local relationships, emphasizing the importance of bridging social capital and human capital (capability and capacity).

\section{Recovering from earthquake}

The second example is the large magnitude $\left(M_{w} 7.8\right)$ earthquake which struck the region in November 2016. The HurunuiKaikōura earthquake (named for the most severely affected regions) had its epicenter in the district and involved 21 faults rupturing over an area of $200 \mathrm{~km}^{2}$. Extensive ground motion resulted in significant damage with thousands of co-seismic landslides, resulting in the closure of much of the main arterial route, State Highway 1, for over a year (Stevenson et al. 2017). Distributed infrastructure such as water and power were also disrupted, including a significant quantity of stored stock water. This event occurred at the apex of the drought, and one participant noted that she did not see her husband for three days post-quake, because he was busy fixing stock water tanks throughout the farm. There were significant negative flow-on effects for the entire economy, in particular tourism, primary sector productivity, and social and psychological well-being (Stevenson et al. 2017, Cradock-Henry et al. 2019, Spector et al. 2019, Fountain and Cradock-Henry 2020). The widespread damage (Stevenson et al. 2017) precipitated a coordinated response through multiple organizations (Trotter and Ivory 2018).

The most common theme relating to the government response and its influence on farmer well-being and resilience from the interview data, was stress. Hurunui Mayor Winton Dalley stated that when you are talking about people post-disaster, "stress is probably the number one issue." Stress, however, is complex, nuanced, and influenced by many factors such as financial stress, animal welfare, and mental health. It is also contextual: everyone's circumstances are unique. Ultimately, Dalley argued that some aspects of the response from the government inadvertently increased stress levels, and therefore had a negative impact: "The intent from ministers is almost always flawless ... but the official response from departments and officials is like chalk and cheese."

For example, part of central government's recovery package included funding for uninsurable on-farm infrastructure, e.g., fences, farm tracks, culverts, and bridges. To be eligible for funding, applicants needed to meet stringent criteria and provide evidence of the financial costs. However, there was no acknowledgement of the considerable time and effort the applications demanded from farmers dealing with the earthquake and its impacts. One respondent, a senior government official, suggested because it was extremely difficult to establish meaningful criteria to account for individuals' social and human capital costs, they were not considered. For human capital, the demands on farmers' time to complete paperwork to evidence their claims lowered their capacity to respond to other priorities during the crisis. This generated additional stress, negatively affecting mental well-being, which negatively impacted linking social capital, because the process caused significant frustration among local farmers, and generated distrust for those responsible. Flow-on effects were also observed, as the net outcome also adversely affected financial and natural capital, with many farmers simply opting out because of the onerous application process, despite being entitled to it. Post-event pamphlets and newsletters show the local Mayor pleading with farmers to engage so they would receive compensation.

In one official's view, the downsides (negative impacts on social and human capital: distrust and stress) outweighed the benefits (fairness/equity in the provision of financial assistance) citing the Australian government's (2018) universal approach to compensation following adverse events as something that should be given more consideration. However, as another government official noted, if farmers know the government will compensate them for their losses, they may be less inclined to prepare and mitigate future losses. The primary sector recovery policy states: "the Crown is not the insurer of first or last resort" (Ministry for Primary Industries 2016), thus relief funding criteria were deliberately strict, in part, to incentivize preparedness. We do not suggest that there is an optimal decision here; clearly there is a balance that must be struck. Rather, we emphasize that it is extremely important to understand the trade-offs that are a part of the decision-making process, and to account for the intangible costs incurred in these decisions. Although a number of officials were aware of the problem, in their view it was never adequately considered in the decision-making process because of the visibility of the data, or lack thereof.

\section{Managing biosecurity risk}

The third example is $M$. bovis, a bacterial disease affecting cattle, but posing no risk to humans that occurred in the region from 2017. As the world's largest exporter of dairy products, the $M$. bovis incursion represented a significant economic risk if left unchecked (Ministry for Primary Industries 2019a). Because $M$. bovis was a novel risk (there were no previous cases in NZ) it was an extremely complex event involving significant uncertainty around testing and potential spread patterns (Ministry for Primary Industries 2019b). Soon after its detection, a decision was made to attempt to eradicate the disease (rather than controlling its spread). Eradication required widespread culling 
of infected cattle. In some cases, all stock from affected farms were compulsorily acquired (Ministry for Primary Industries 2019c), with traumatic implications for farmers that persist to this day. The testing process was repeatedly questioned because of false positive test scores, and multiple rounds of testing were often required. Farmers and regional officials cited examples of official process being bypassed to pay for independent expert analysis to prove that their cattle were not infected and did not have to be culled. Farmers were unable to move stock for extended periods, except to slaughter, compounding uncertainty, frustration, and confusion about the need for culling. Across the region, there were significant concerns about communication and transparency, and the implications for confidence and trust in the decision-making and monitoring processes. The result was a negative impact on linking social capital, illustrated by reduced trust in government officials. As one farmer said, "so the trust thing, it probably comes down to ... if MPI [as the agency responsible for biosecurity] got in contact with me tomorrow about anything, I'd say no, I need to do my background and talk to legal advice and see where I stand with whatever it is." He described his initial willingness to engage in good faith with the MPI process as naïve.

Conversations with those involved in the response were candid, describing how they were aware of the issues and were working on it as best they could. They described how the initial response had focused on disease control with no consideration given to the human impacts, but how the focus had shifted once the negative outcomes became apparent. Respondents described an overall lack of capacity and capability (human capital) to deal with a problem of this scale in regional and central government, which required a coordinated, rapid, and wide-reaching response over a short period of time. Multiple respondents recalled there had once been a "Rural Social Policy" unit within MPI that had built significant linking social capital with farmers through strong relationships and trusted knowledge whose mandate had been to deal with these types of crises. The program had been restructured out of existence over a decade ago because of a lack of evidence for the financial justification of the program. Multiple participants (public and private domain) wondered how things could have been different if it had still existed. Reflecting on their own involvement with the systemic restructuring of public services at that time, one interviewee highlighted its significance for rural communities in the following terms: "The effect [of restructuring] was to strip out human capital ... a stripping of capability at [MPI], and they had a substantially diminished capability and I attribute some of our biosecurity failings since then to that lack of capability." This is just one example of how evidence-based policy put the focus squarely on financial capital and failed to account for the intangible impacts of social and human capital, resulting in negative outcomes during this crisis. It also showcases how a short-term focus on efficiency can have negative consequences for resilience in the longer term, illuminating the tension between efficiency and persistence. In this case, the loss of capability and capacity had direct and indirect effects on MPI's ability to maintain relationships with some rural communities, reducing trust, and hindering effective responses during the $M$. bovis incursion.

Recent media reports have described initial discussions about reestablishing a new rural social policy unit. When queried, interviewees were doubtful about the effectiveness of reinstating it, arguing that the institutional knowledge and relationships (social and human capital) were already lost, and would require considerable investment and time to rebuild; far more than it would have cost to simply keep the program running. Understanding and systemically accounting for these factors during decision-making processes is essential. One participant with over 30 years' experience at the highest levels stated that they were "deeply concerned about NZ's ability to learn from its mistakes," and that we seem to be repeating them. A key problem here is visibility of the issues. Many of the problems described here are intangible, subjective, and do not easily lend themselves to traditional governance tools and legislative instruments such as targets and indicators. The LSF, combined with resilience thinking, makes these issues visible on a systemic level in a way that they were not before.

\section{DISCUSSION}

Results from the case examples illustrate the extent to which social and/or human capital have been important factors in determining the effectiveness of policy responses to the adverse events, intentionally or otherwise. It should be made clear that the results discussed in this paper are not presented in order to attribute blame to any party. Rather, the intent is to demonstrate the value of resilience thinking in conjunction with the LSF for examining how institutional responses to adverse events might be improved, and how the ideological and institutional settings have shaped outcomes. A thorough understanding of these processes, aided by analysis through the LSF, can help contextualize the impacts of future events, improve policy responses, and help generate good outcomes.

Operationalizing SES resilience is challenging, especially in the social domain and policy and practice where key paradigm shifts have been ignored in favor of traditional analytical tools. In NZ, the LSF and NDRS are a response to the recognition of these challenges, and they work hand-in-hand as part of the government's efforts to meet its commitments under the Sendai Framework for Disaster Risk Reduction. This approach offers unique opportunities to analyze how the concepts of social and human capital can refocus SES resilience thinking toward the value of qualitative analysis, which Holling's (1973) initial conceptualization of resilience considered of paramount importance. Here, we reflect on the three adverse events, the responses to them, and the resulting outcomes, to illustrate the three interlinked challenges - nuance, norms, and measurement - and discuss how the LSF can help operationalize resilience thinking in more robust ways for policy and practice.

\section{Nuances of resilience}

The rapid adoption of resilience in policy and practice has inadvertently multiplied interpretations and applications of the concept. The result is a less nuanced understanding of the differences between engineering and social-ecological framings of resilience (Endress 2015). This nuance and complexity (specifically the qualitative focus) surrounding resilience thinking has been lost in the simplified definitions that have been rapidly distributed among policy makers and practitioners. For resilience thinking to be an effective antidote to negative outcomes of disaster, it is important that the nuance of the paradigm shifts are understood from a policy perspective. 
The problems associated with the loss of nuance are not new and were first highlighted by Holling (1973) in his distinction between SES and engineering resilience. Engineering resilience emphasizes efficiency, constancy, predictability, and certainty, whereas socialecological resilience in contrast emphasizes the opposing principles of persistence, change, unpredictability, and uncertainty (Table 1). Events in the Hurunui were typically complex, with interrelated and interacting social, economic, and environmental characteristics. Policy makers and practitioners, therefore, were confronted with a lack of predictable outcomes of interventions, considerable uncertainty, contested problem definitions and framings, and the diverse perspectives and values of affected communities and residents. Greater clarity might have been gained by viewing events through the lens of linked socialecological systems, which would emphasize the importance of human outcomes - capacity and capability, social and human capital-allowing for enhanced engagement between those responding and those impacted rather than just holding a narrow focus on economic outcomes.

Strategic government risk reduction measures must consider the full range of known and unknown risks, and their scale and frequency. For example, "known unknowns" are societal risks with high public awareness, such as earthquakes on known fault lines or pandemics, whereas "unknown unknowns" are rare and unpredictable with major consequences. Second, high frequency yet low consequence events, such as perennial weather-related hazards, exist in contrast with infrequent yet high consequence events such as an eruption in the Auckland volcanic field. A senior government official with extensive experience in the sector observed:

\section{We have limited resources with which to plan for events, and while it's easy to spendmoney preparing for resilience to specific events, the most damaging and costly events are rarely what we plan for. General resilience is much more useful in a wide variety of situations, but it is also much more difficult and expensive to build.}

The most damaging and costly events are often accompanied by significant uncertainty and unpredictability, and are better suited to a social-ecological resilience approach. The more common events whose parameters are better known can still be addressed using traditional engineering resilience approaches.

As we noted earlier, these two approaches should not be seen as competing, but rather as complementary. There are merits and downsides to both approaches; as risk and vulnerability become better understood, and objectively quantified, engineering resilience approaches that assume certain levels of certainty and predictability can be very useful. Relatively frequent extreme weather events have predictable consequences that can be effectively mitigated through existing strategies. However, this approach is less effective in areas of significant uncertainty and complexity such as the unpredictable and compounding impacts of climate change, biosecurity outbreaks, or pandemics. A socialecological systems approach to resilience is much more beneficial for these types of events. Accordingly, both approaches will always be relevant and will complement one another.

Ultimately, utilizing the LSF to frame these issues does not inherently or automatically solve the problem of the lack of nuance, but it does help address it by providing a framework which makes the qualitative factors as well as the inherent systemic complexity more visible. The LSF was created as a tool to guide public sector decision making by the NZ Treasury (2019) and, as demonstrated above, it has value when navigating trade-offs, especially those associated with the intangible phenomena related to social and human capital. By incorporating the LSF, disaster recovery becomes about more than just "bouncing back" with commensurate targets and indicators for natural and physical/ financial capital, the qualitative factors associated with social and human capital are also accounted for. During the Kaikōura earthquake response, for example, eligibility criteria for financial aid did not take into account the costs to human and social capital that led to negative outcomes. However, applying the LSF automatically makes the intangible phenomena more visible on a systemic level, focusing attention on social and human capital allowing for those factors to be better considered during the decision-making process. We do not make an ex-post assessment of the correct decision to be made in this context, rather, we emphasize the importance of systematically taking all factors into account a priori when making decisions. For example, this approach enables positive accounting of intangible benefits such as those provided by RSTs that might otherwise not appear on budget sheets.

\section{Normative dimensions of resilience}

Reflecting on farmers' and support agencies' experiences in the Hurunui can also be used to evaluate the effectiveness of postevent response and recovery. A resilience perspective, informed by the LSF, offers an opportunity to better understand the social dimensions of resilience, including aspects of social theory. The LSF aims to account for key resources that confer value to NZ but may not have previously been measured or are not suited to quantification (Frieling and Warren 2018). For example, how would one characterize the lack of trust caused by years of eroded specialist capability in MPI due to fiscal restructuring, which culminated in insufficient capacity for a social response following a biosecurity threat? The issue here was of quantification: the NZ government's approach to financial accountability was evidencebased but did not account for the negative impacts on social and human capital, and therefore these aspects were not considered. Incorporating the LSF and multiple types of capital stocks, each of which are uniquely influenced by policy, has the potential to allow for new ideas, debates, and discourses. Suddenly that which is not measured (or is not easily measurable) becomes visible on a systemic level within a public policy framework developed to identify these types of phenomena. It is important to note that this heuristic is not just about detailing or creating new understandings, rather it becomes about systematizing them within a whole of government approach through a collective understanding of the problem.

Through using the LSF alongside resilience thinking as an analytic tool, the loss of the MPI's social policy unit illustrates that inadequate attention was paid to linking social capital during the review of the program. This then negatively impacted bonding, bridging, and linking social capital and human capital during the responses, which in turn indirectly influenced physical/ economic and natural capital. Social and human capital incorporate a range of important factors such as institutional 
trust and unequal power dynamics. Such factors fit comfortably within the LSF and can be analyzed comparatively alongside the other capitals.

On one level, prior to the economic crisis of the 1980s NZ could be described as having relatively high levels of social and human capital, but low levels of economic capital (Kelsey 1995). External shocks, including falling wool prices and the Yom Kippur oil price shock, combined with poor management (Templeton 1995), took $\mathrm{NZ}$ to a threshold where the transition into a new stable state of economic collapse was only barely averted. As one interviewee who had been involved in the restructuring stated: "we saved the patient [NZ], barely." This crisis had a transformative impact on NZ's fiscal management, with an overwhelming focus on fiscal prudence and evidence-based policy during the years that followed (Kelsey 1995). Utilizing the LSF, this research provides strong evidence that subsequent restructuring placed an overwhelming emphasis on financial/physical capital at the cost of social and human capital. This was not an explicit and intentional focus, but the shift in arrangements demanded that policy be designed based on evidence. Economic factors were the simplest to measure, in contrast to the intangible aspects of social resilience encapsulated within social and human capital. As noted earlier, "what we measure affects what we do. If we measure the wrong thing, we will do the wrong thing. If we don't measure something, it becomes neglected, as if the problem didn't exist" (Stiglitz et al. 2018:13).

More locally, results illustrate how social and human capital are both positively and negatively impacted by institutional responses following adverse events. Strong relationships between the RSTs and local farmers delivered the most effective results of all. However, the case example also revealed potential thresholds, where overreliance on the RSTs might result in the breakdown of relationships, i.e., bridging and linking social capital, which then impacts all other capital stocks. This may result in a new stable state where an extremely effective support tool no longer exists. Following the earthquake in the Hurunui, officials required verifiable evidence of loss before compensation payments were made, in order to ensure equitable outcomes for those who had taken proactive risk management strategies. The negative impacts of these policies were unquantified and therefore invisible, but led to a perception that seeking compensation created more negative than positive outcomes. During the M. bovis response, previously strong and trusted relationships were broken by the loss of MPI's Social Policy Unit, causing a significant breakdown in trust developed between farmers and MPI over many years, which manifested in poor outcomes during the response.

\section{Measuring resilience}

The problem of measurement remains challenging. Incorporating the LSF alongside resilience thinking does not offer any concrete ways to better objectively measure the intangible factors often associated with social resilience. This result is consistent with international research, which also highlights these challenges (Cutter et al. 2008, 2014, Cutter 2016). It also reflects broader issues and appeals in social science literature for objectively measuring social capital (Harper 2002, Halpern 2005, Scrivens and Smith 2013, Field 2016). The problem here is context. Targets, indicators, and legislative instruments are effective and appropriate mechanisms for dealing with data that is objectively quantifiable, some examples of which are the structural indicators of resilience proposed by Kwok et al. (2016; Table 2). However, the cognitive indicators he proposes are equally important but subjective. They do not readily lend themselves to effective quantification because they are context-specific, and they are difficult to compare across case settings.

Institutional trust has been highlighted by this research as being an influential factor across all three responses: the drought, earthquake, and M. bovis. However, the factors that influenced such trust were highly context dependent and unique to each case. In the drought, the trusted relationships between the RSTs and local farmers were cited as exceptionally important, with the government minimizing its role in funding the RSTs to ensure RSTs were seen by farmers as being independent of government. After the earthquake, the way in which the government applied eligibility criteria damaged trust, drawing accusations that they only cared about money, and not about people. The earlier dismantling of the rural social policy unit significantly curtailed the capacity and ability for the government to respond effectively during the $M$. bovis crisis, which further damaged trust. Trust is clearly an important indicator of social resilience. Yet measuring trust objectively without the relevant contextual factors provides limited useful data (Lacey et al. 2018). The levels of trust are important, but equally so is what influences it, and how to effect it. Quantification of trust is not useful without a deeper understanding of the context and associated complexities, which only in-depth qualitative data can provide.

Ultimately, the problem of measurement for the normative issues described herein may not be solvable through only the use of current accountability mechanisms such as targets and indicators. Although proxy indicators can be used in their place, they are often associated with perverse incentives, outcomes and other pitfalls (Carpenter et al. 2001, Birkmann 2007, Dakos et al. 2015, Hallegatte and Engle 2019). Research participants familiar with the process of developing the LSF confided doubts as to whether it is possible to adequately measure cognitive resilience indicators. The problem cited was context, in that lessons learned in one case are not necessarily transferable to another without a deeper qualitative understanding of why and how (Adler et al. 2018). Holling's (1973:1) rejoinder to natural equilibrium theory stated that it was "an analytic approach developed in one area because it was useful and then transferred to another where it may not be." A quantitative approach comprising targets and indicators are useful tools for dealing with objectifiable data, but they fall short when dealing with that which is normative or subjective, where a qualitative approach is more appropriate.

Theoretically, applying a qualitative lens for resilience thinking should not be problematic. It is, in fact, consistent with some of the earliest reflections on the subject. Holling (1973:1) observed the following:

If we are dealing with a system profoundly affected by changes external to it, and continually confronted by the unexpected, the constancy of its behavior becomes less important than the persistence of the relationships. Attention shifts, therefore, [from the quantitative] to the qualitative and to questions of existence or not [emphasis added]. 
Resilience thinking was designed to provide mechanisms to analyze ecosystem phenomena that are not fully quantifiable. It is inherently qualitative. This original paradigm shift is now being rediscovered, which addresses the problem of nuance. It is, however, important to reiterate that both qualitative and quantitative methodologies will remain equally important for disaster risk reduction.

A promising mechanism to account for the problem of measurement in a qualitative sense is the participatory turn in resilience, the emphasis on co-producing knowledge to bridge the gap between science and policy (Vallance 2015, Kwok et al. 2016, Cradock-Henry et al. 2019). As the Sendai Framework states, shared engagement amongst all stakeholders is vital (UNISDR 2015). Although data collection for this research focused on the effectiveness of institutional decision making and governance arrangements, the narrative was structured by those who experienced the events at the local level because those participants were interviewed first and set the scene. Beginning at the top and snowballing top down, or only interviewing government and organizations would have resulted in a very different picture of what occurred and what was needed. Co-production of knowledge from those at the coalface provided valuable insight into the whole picture.

Regardless, evidence-based decision making will continue to play an important role in our institutions and governance structures. The inability to adequately measure key sources of value in our communities is problematic. Kaika's (2017) reflection that we need to change both what we do, as well as how we do it draws attention to the need to find different ways to address this problem. Although it may not be possible to adequately quantify subjective indicators, the LSF framework, combined with resilience thinking, provides new ways of thinking about these problems, and how to bring them into the policy domain. Focusing on process-based indicators as part of policy or project design and implementation might offer a more robust alternative for indicator development (Hallegatte and Engle 2019). Quantitative indicators for trust might be better addressed in the design phase of policy response, ensuring that adequate attention is paid to those matters at the beginning, rather than during the outcome evaluation stage (Cradock-Henry et al. 2017). A qualitative view rich in context is more appropriate for outcome evaluation with subjective cognitive indicators that demand context-specific knowledge.

In the case example of the rural social policy unit that was restructured out of existence, if explicit focus was paid to social and human capital, and questions were asked as to the impacts of restructuring, and these factors were taken into account, a different view might have been taken as to whether eliminating it completely was acceptable. This could have occurred at a high level and would not have required quantifiable indicators for outcomes, but acknowledgement of the importance of social and human capital visible within a systemic framework such as the LSF. This has the added advantage of proactively dealing with potential problems, rather than reactively. A qualitative view rich in context after the restructuring can only shine a light on what was lost but cannot regain it.

Finally, it is important to highlight the interlinked nature of the three challenges discussed. The problem of measurement is clearly related to the normative issues, as well as the problem of nuance. The normative issues described herein are primarily subjective, and not objectively quantifiable, hence, current legislative instruments such as targets and indicators do not account for them. The loss of nuance relates to the rapid transmission and uptake of resilience thinking into the policy domain, and these complexities associated with resilience thinking are not easily demonstrated because of a lack of clear objective evidence, or measurable phenomena. At the heart of both of these challenges, is the problem of measurement. As Stiglitz (2018:13) notes, "If we don't measure something, it becomes neglected, as if the problem didn't exist." The intangible aspects of resilience, therefore, are invisible in an evidence-based decision-making framework. They are also circular. One problem influences and creates the other. Adopting the LSF alongside SES resilience thinking does not provide clear cut solutions to any of these challenges on an individual basis. It does, however, make that which is unseen, visible. And in doing so, it draws attention to each of these three challenges, illustrating the problems that they pose. The first step to solve a problem is to understand it. With this paper we do not set out to provide categorical solutions for these challenges, rather, we clarify the role resilience thinking plays in public policy design (such as adverse event responses) and use the LSF to make critical intangible factors more visible and recognizable (by utilizing the concepts of social and human capital), thus allowing for them to be addressed by future research and policy.

\section{CONCLUSIONS}

Resilience concepts are being rapidly adopted as part of global efforts aimed at disaster risk reduction. Public officials from all nations will continue to make decisions on complex topics with considerable uncertainty and an insufficient evidence base. An SES resilience approach that assumes uncertainty, unpredictability, and constant change reflects the important paradigm shift that resilience thinking entails and is becoming entrenched in policy domains worldwide. Although there are challenges to its uncritical use in policy and practice, SES resilience does provide useful theoretical, conceptual, and processual tools to support outcomes for communities following a disaster. As shown in the case-studies, addressing the three challenges - loss of nuance, making clear the underlying normative dimensions of resilience, and enhancing the visibility of previously intangible social and human capitals - can add value and strengthen the capacity of resilience thinking to deliver theoretical and practical outcomes. Combining SES resilience with a multi-capital framework, such as the LSF, shows significant potential in beginning to address these challenges by making them visible on a systemic level. Results from the case examples illustrate how government, policy makers, and practitioners can use the LSF for this purpose.

These conclusions have significant, but varied, implications for research, policy, and practice. Academically, resilience theory draws attention to the qualitative (Holling 1973). The addition of the social dimension into resilience thinking in the early 2000 s (the "social" in social-ecological systems) provides an opportunity for SES resilience thinking to continue to engage with existing social qualitative literature, in particular to engage more fully and critically with normative issues such as equality, power, and justice, realizing its potential as a boundary object (Baggio et al. 2015). 
The implications for policy and practice are more profound. SES resilience's rapid adoption into the policy domain by the Sendai Framework for Disaster Risk Reduction has been characterized by repeated attempts to use quantitative methodologies and legislative instruments such as targets and indicators for implementation. This approach has yet to prove successful, and its ability to succeed is in doubt. It relies upon evidence-based decision making, which is inherently quantitative in nature. This highlights the nuance problem, as well as the problem of measurement. Key factors of resilience are not easily measurable, yet they must be accounted for. Resilience thinking is designed to account for that which is not quantifiable, making it an ideal tool to incorporate the normative dimensions. This necessitates a significant change in how policy and practice must operate. Incorporating a multi-capital framework, such as the LSF, alongside resilience thinking provides a path forward.

Responses to this article can be read online at: https://www.ecologyandsociety.org/issues/responses. $\mathrm{php} / 12409$

\section{Acknowledgments:}

This research was funded by the Resilience to Nature's Challenges National Science Challenge through the NZ Ministry of Business Innovation and Employment, as part of the Rural Co-Creation Laboratory and Cultural Toolbox. We also gratefully acknowledge all interview participants and the thoughtful comments of the two anonymous reviewers. This project was (partially) supported by QuakeCoRE, a New Zealand Tertiary Education Commissionfunded Centre. This is QuakeCoRE publication number 0665.

\section{Data Availability:}

This research involved human participants and we used a process of informed consent. We received approval to conduct this research through the University of Otago Human Ethics Committee (Reference Number: 18/060). Each interview was audio-recorded and transcribed by the lead author. All names were omitted from transcripts to preserve privacy, including any distinguishing characteristics associated with individual respondents. Because of the nature of this research, participants of this study did not agree for their data to be shared publicly, so supporting data is not available.

\section{LITERATURE CITED}

Adger, W. N., I. Brown, and S. Surminski. 2018. Advances in risk assessment for climate change adaptation policy. Philosophical Transactions of the Royal Society A 376(2121):20180106. https:// doi.org/10.1098/rsta.2018.0106

Adger, W. N., T. P. Hughes, C. Folke, S. R. Carpenter, and J. Rockström. 2005. Social-ecological resilience to coastal disasters. Science 309(5737):1036-1039. https://doi.org/10.1126/science.1112122

Adler, C., G. H. Hadorn, T. Breu, U. Wiesmann, and C. Pohl. 2018. Conceptualizing the transfer of knowledge across cases in transdisciplinary research. Sustainability Science 13:179-190. https://doi.org/10.1007/s11625-017-0444-2

Aitsi-Selmi, A., K. Blanchard, and V. Murray. 2016. Ensuring science is useful, usable and used in global disaster risk reduction and sustainable development: a view through the Sendai framework lens. Palgrave Communications 2:16016. https://doi. org/10.1057/palcomms.2016.16

Aitsi-Selmi, A., S. Egawa, H. Sasaki, C. Wannous, and V. Murray. 2015. The Sendai framework for disaster risk reduction: renewing the global commitment to people's resilience, health, and wellbeing. International Journal of Disaster Risk Science 6:164-176. https://doi.org/10.1007/s13753-015-0050-9

Aldrich, D. 2012. Building resilience: social capital in postdisaster recovery. University of Chicago Press, Chicago, Illinois, USA. https://doi.org/10.7208/chicago/9780226012896.001.0001

Aldunce, P., R. Beilin, M. Howden, and J. Handmer. 2015. Resilience for disaster risk management in a changing climate: practitioners' frames and practices. Global Environmental Change 30:1-11. https://doi.org/10.1016/j.gloenvcha.2014.10.010

Alexander, D. E. 2013. Resilience and disaster risk reduction: an etymological journey. Natural Hazards and Earth System Science 13(11):2707-2716. https://doi.org/10.5194/nhess-13-2707-2013

Arbon, P., M. Steenkamp, V. Cornell, L. Cusack, and K. Gebbie. 2016. Measuring disaster resilience in communities and households: pragmatic tools developed in Australia. International Journal of Disaster Resilience in the Built Environment 7 (2):201-215. https://doi.org/10.1108/IJDRBE-03-2015-0008

Aryal, A., and S. Wilkinson. 2019. The role of social capital in the recovery of cultural built heritage: evidence from three heritage sites in Nepal, International Journal of Disaster Resilience in the Built Environment 11(1):44-57. https://doi. org/10.1108/IJDRBE-06-2019-0033

Australian Government. 2018. Disaster recovery payment. Australian Government, Melbourne, Australia. [online] URL: https://www.disasterassist.gov.au/Pages/disaster-recovery-payment. $\underline{\operatorname{aspx}}$

Baggio, J. A., K. Brown, and D. Hellebrandt. 2015. Boundary object or bridging concept? A citation network analysis of resilience. Ecology and Society 20(2):2. https://doi.org/10.5751/ ES-07484-200202

Bahadur, A., and T. Tanner. 2014. Transformational resilience thinking: putting people, power and politics at the heart of urban climate resilience. Environment and Urbanization 26(1):200-214. https://doi.org/10.1177/0956247814522154

Barnett, J., and J. Pauling. 2005. The environmental effects of New Zealand's free-market reforms. Environment, Development and Sustainability 7(2):271-289. https://doi.org/10.1007/s10668-005-7316-0

Bebbington, A. 1999. Capitals and capabilities: a framework for analyzing peasant viability, rural livelihoods and poverty. World Development 27(12):2021-2044. https://doi.org/10.1016/S0305-750X (99)00104-7 
Berkes, F., and C. Folke, editors. 2000. Linking social and ecological systems: management practices and social mechanisms for building resilience. Cambridge University Press, Cambridge, UK.

Berkes, F., and H. Ross. 2013. Community resilience: toward an integrated approach. Society \& Natural Resources 26:5-20. https://doi.org/10.1080/08941920.2012.736605

Birkmann, J. 2007. Risk and vulnerability indicators at different scales: applicability, usefulness and policy implications. Environmental Hazards 7(1):20-31. https://doi.org/10.1016/j. envhaz.2007.04.002

Bowen, K. J., N. A. Cradock-Henry, F. Koch, J. Patterson, T. Häyhä, J. Vogt, and F. Barbi. 2017. Implementing the "sustainable development goals": towards addressing three key governance challenges - collective action, trade-offs, and accountability. Current Opinion in Environmental Sustainability 26-27:90-96. https://doi.org/10.1016/j.cosust.2017.05.002

Bronen, R. 2015. Climate-induced community relocations: using integrated social-ecological assessments to foster adaptation and resilience. Ecology and Society 20(3):36. https://doi.org/10.5751/ ES-07801-200336

Brown, K. 2014. Global environmental change I: a social turn for resilience? Progress in Human Geography 38(1):107-117.

Brown, K., and E. Westaway. 2011. Agency, capacity, and resilience to environmental change: lessons from human development, well-being, and disasters. Annual Review of Environment and Resources 36(1):321-342. https://doi. org/10.1146/annurev-environ-052610-092905

Brundiers, K., and H. C. Eakin. 2018. Leveraging post-disaster windows of opportunities for change towards sustainability: a framework. Sustainability 10(5):1390. https://doi.org/10.3390/ $\underline{\text { su10051390 }}$

Burton, R. J. F., and S. Peoples. 2014. Market liberalisation and drought in New Zealand: a case of 'double exposure' for dryland sheep farmers? Journal of Rural Studies 33:82-94. https://doi. org/10.1016/j.jrurstud.2013.11.002

Calderón-Contreras, R., and C. S. White. 2020. Access as the means for understanding social-ecological resilience: bridging analytical frameworks. Society \& Natural Resources 33 (2):205-223. https://doi.org/10.1080/08941920.2019.1597233

Cannon, T., and D. Müller-Mahn. 2010. Vulnerability, resilience and development discourses in context of climate change. Natural Hazards 55(3):621-635. https://doi.org/10.1007/s11069-010-9499-4

Carpenter, S., B. Walker, J. M. Anderies, and N. Abel. 2001. From metaphor to measurement: resilience of what to what? Ecosystems 4(8):765-781. https://doi.org/10.1007/s10021-001-0045-9

Cloke, P. 1996. Rural life-styles: material opportunity, cultural experience, and how theory can undermine policy. Economic Geography 72(4):433-449. https://doi.org/10.2307/144523

Connelly, E. B., C. R. Allen, K. Hatfield, J. M. Palma-Oliveira, D. D. Woods, and I. Linkov. 2017. Features of resilience. Environment Systems and Decisions 37(1):46-50. https://doi. org/10.1007/s10669-017-9634-9
Cote, M., and A. J. Nightingale. 2012. Resilience thinking meets social theory: situating social change in socio-ecological systems (SES) research. Progress in Human Geography 36(4):475-489. https://doi.org/10.1177/0309132511425708

Cradock-Henry, N. A., F. Buelow, and J. Fountain. 2019. Socialecological inventory in a postdisaster context: the 2016 Kaikōura earthquake, Aotearoa-New Zealand. Ecology and Society 24 (3):9. https://doi.org/10.5751/es-11075-240309

Cradock-Henry, N. A., J. Fountain, and F. Buelow. 2018. Transformations for resilient rural futures: the case of Kaikōura, Aotearoa-New Zealand. Sustainability 10(6):1952. https://doi. org/10.3390/su10061952

Cradock-Henry, N. A., S. Greenhalgh, P. Brown, and J. Sinner. 2017. Factors influencing successful collaboration for freshwater management in Aotearoa, New Zealand. Ecology and Society 22 (2):14. https://doi.org/10.5751/ES-09126-220214

Cretney, R., and S. Bond. 2014. 'Bouncing back' to capitalism? Grass-roots autonomous activism in shaping discourses of resilience and transformation following disaster. Resilience 2 (1):18-31. https://doi.org/10.1080/21693293.2013.872449

Cutter, S. L. 2016. The landscape of disaster resilience indicators in the USA. Natural Hazards 80(2):741-758. https://doi. org/10.1007/s11069-015-1993-2

Cutter, S. L., K. D. Ash, and C. T. Emrich. 2014. The geographies of community disaster resilience. Global Environmental Change 29:65-77. https://doi.org/10.1016/j.gloenvcha.2014.08.005

Cutter, S. L., L. Barnes, M. Berry, C. Burton, E. Evans, E. Tate, and J. Webb. 2008. A place-based model for understanding community resilience to natural disasters. Global Environmental Change 18(4):598-606. https://doi.org/10.1016/j.gloenvcha.2008.07.013

Cutter, S. L., A. Ismail-Zadeh, I. Alcántara-Ayala, O. Altan, D. N. Baker, S. Briceño, H. Gupta, A. Holloway, D. Johnston, G. A. McBean, Y. Ogawa, D. Paton, E. Porio, R. K. Silbereisen, K. Takeuchi, G. B. Valsecchi, C. Vogel, and G. Wu. 2015. Global risks: pool knowledge to stem losses from disasters. Nature 522 (7556):277-279. https://doi.org/10.1038/522277a

Dakos, V., S. R. Carpenter, E. H. van Nes, and M. Scheffer. 2015. Resilience indicators: prospects and limitations for early warnings of regime shifts. Philosophical Transactions of the Royal Society B: Biological Sciences 370(1659):20130263. https://doi. org/10.1098/rstb.2013.0263

Davidson, D. 2016. Gaps in agricultural climate adaptation research. Nature Climate Change 6:433-435. https://doi. org/10.1038/nclimate3007

Dovers, S. R., and A. A. Hezri. 2010. Institutions and policy processes: the means to the ends of adaptation. Wiley Interdisciplinary Reviews: Climate Change 1(2):212-231. https:// doi.org/10.1002/wcc.29

Durlauf, S. N. 1999. The case 'against' social capital. Focus 20 (3):1-5.

Endress, M. 2015. The social constructedness of resilience. Social Sciences 4:533-545. https://doi.org/10.3390/socsci4030533 
Federated Farmers of New Zealand. 2001. Life after subsidies. Third edition. Federated Farmers, Wellington, New Zealand.

Field, J. 2016. Social capital. Third Edition. Taylor \& Francis, London, UK.

Folke, C. 2016. Resilience (Republished). Ecology and Society 21 (4):44. https://doi.org/10.5751/ES-09088-210444

Fountain, J., and N. A. Cradock-Henry. 2020. Recovery, risk and resilience: post-disaster tourism experiences in Kaikōura, New Zealand. Tourism Management Perspectives 35:100695. https:// doi.org/10.1016/j.tmp.2020.100695

Frieling, M. 2018. The start of a conversation on the value of New Zealand's social capital. New Zealand Treasury, Wellington, New Zealand. [online] URL: https://treasury.govt.nz/sites/ default/files/2018-02/dp18-04.pdf

Frieling, M., and K. Warren. 2018. Resilience and future wellbeing: the start of a conversation on improving the risk management and resilience of the Living Standards Capitals. New Zealand Treasury, Wellington, New Zealand. [online] URL: https://treasury.govt.nz/sites/default/files/2018-07/dp18-05.pdf

Garmezy, N., A. S. Masten, and A. Tellegen. 1984. The study of stress and competence in children: a building block for developmental psychopathology. Child Development 55 (1):97-111. https://doi.org/10.2307/1129837

Goodhart, C. 1975. Problems of monetary management: the U. $\mathrm{K}$. experience. Papers in Monetary Economics. 1. Reserve Bank of Australia, Sydney, Australia.

Gray, S., and R. Le Heron. 2010. Globalising New Zealand: Fonterra Co-operative Group, and shaping the future. New Zealand Geographer 66(1):1-13. https://doi.org/10.1111/ j.1745-7939.2010.01173.x

Hajer, M., M. Nilsson, K. Raworth, P. Bakker, F. Berkhout, Y. de Boer, J. Rockström, K. Ludwig, and M. Kok. 2015. Beyond cockpit-ism: four insights to enhance the transformative potential of the sustainable development goals. Sustainability 7 (2):1651-1660. https://doi.org/10.3390/su7021651

Hallegatte, S., and N. L. Engle. 2019. The search for the perfect indicator: reflections on monitoring and evaluation of resilience for improved climate risk management. Climate Risk Management 23:1-6. https://doi.org/10.1016/j.crm.2018.12.001

Halpern, D. 2005. Social capital. Polity, Cambridge, UK.

Harper, R. 2002. The measurement of social capital in the United Kingdom. Office for National Statistics, Newport, UK. [online] URL: http://search.oecd.org/education/innovation-education/2382339. pdf

Hayward, B. M. 2013. Rethinking resilience: reflections on the earthquakes in Christchurch, New Zealand, 2010 and 2011. Ecology and Society 18(4):37. https://doi.org/10.5751/es-05947-180437

Hewitt, K. 2013. Environmental disasters in social context: toward a preventive and precautionary approach. Natural Hazards 66:3-14. https://doi.org/10.1007/s11069-012-0205-6

Holling, C. S. 1973. Resilience and stability of ecological systems. Annual Review of Ecology and Systematics 4(1):1-23. https://doi. org/10.1146/annurev.es.04.110173.000245
Holling, C. S. 1996. Engineering resilience versus ecological resilience. Pages 31-44 in P. C. Schulze, editor. Engineering within ecological constraints. National Academy, Washington, D.C., USA.

Holling, C. S. 2001. Understanding the complexity of economic, ecological, and social systems. Ecosystems 4(5):390-405. https:// doi.org/10.1007/s10021-001-0101-5

Jay, M. 2007. The political economy of a productivist agriculture: New Zealand dairy discourses. Food Policy 32(2):266-279. https:// doi.org/10.1016/j.foodpol.2006.09.002

Kaika, M. 2017. 'Don't call me resilient again!': the new urban agenda as immunology ... or ... what happens when communities refuse to be vaccinated with 'smart cities' and indicators. Environment and Urbanization 29(1):89-102. https://doi. org/10.1177/0956247816684763

Karacaoglu, G. 2015. The New Zealand Treasury's living standards framework - exploring a stylised model. Treasury Working Paper Series 15/12, New Zealand Treasury, Wellington, New Zealand.

Kates, R. W., W. R. Travis, and T. J. Wilbanks. 2012. Transformational adaptation when incremental adaptations to climate change are insufficient. Proceedings of the National Academy of Sciences 109(19):7156-7161. https://doi.org/10.1073/ pnas. 1115521109

Kelman, I., J. C. Gaillard, and J. Mercer. 2015. Climate change's role in disaster risk reduction's future: beyond vulnerability and resilience. International Journal of Disaster Risk Science 6 (1):21-27. https://doi.org/10.1007/s13753-015-0038-5

Kelsey, J. 1995. The New Zealand experiment: a world model for structural adjustment? Auckland University Press, Auckland, New Zealand. https://doi.org/10.7810/9781869401306

Kwok, A. H., J. Becker, D. Paton, E. Hudson-Doyle and D. Johnston. 2019. Stakeholders' perspectives of social capital in informing the development of neighborhood-based disaster resilience measurements. Journal of Applied Social Science 13 (1):26-57. https://doi.org/10.1177/1936724419827987

Kwok, A. H., E. E. H. Doyle, J. Becker, D. Johnston, and D. Paton. 2016. What is 'social resilience'? Perspectives of disaster researchers, emergency management practitioners, and policymakers in New Zealand. International Journal of Disaster Risk Reduction 19:197-211. https://doi.org/10.1016/j.ijdrr.2016.08.013

Lacey, J., M. Howden, C. Cvitanovic, and R. M. Colvin. 2018. Understanding and managing trust at the climate science-policy interface. Nature Climate Change 8:22-28. https://doi. org/10.1038/s41558-017-0010-Z

Lei, Y., J. Wang, Y. Yue, H. Zhou, and W. Yin. 2014. Rethinking the relationships of vulnerability, resilience, and adaptation from a disaster risk perspective. Natural Hazards 70(1):609-627. https://doi.org/10.1007/s11069-013-0831-7

Liu, W. T. 2014. The application of resilience assessmentresilience of what, to what, with what? A case study based on Caledon, Ontario, Canada. Ecology and Society 19(4):21. https:// doi.org/10.5751/es-06843-190421 
Manyena, S. B., G. O'Brien, P. O'Keefe, and J. Rose. 2011. Disaster resilience: a bounce back or bounce forward ability? Local Environment 16(5):417-424. https://doi.org/10.1080/13549839.2011.583049

Marshall, N. A., D. M. Fenton, P. A. Marshall, and S. G. Sutton. 2007. How resource dependency can influence social resilience within a primary resource industry. Rural Sociology 72 (3):359-390. https://doi.org/10.1526/003601107781799254

Mikulcak, F., J. L. Haider, D. J. Abson, J. Newig, and J. Fischer. 2015. Applying a capitals approach to understand rural development traps: a case study from post-socialist Romania. Land Use Policy 43:248-258. https://doi.org/10.1016/j. landusepol.2014.10.024

Miller, F., H. Osbahr, E. Boyd, F. Thomalla, S. Bharwani, G. Ziervogel, B. Walker, J. Birkmann, S. van der Leeuw, J. Rockström, J. Hinkel, T. Downing, C. Folke, and D. Nelson. 2010. Resilience and vulnerability: complementary or conflicting concepts? Ecology and Society 15(3):11. https://doi.org/10.5751/es-03378-150311

Ministry for Primary Industries. 2016. Summary of the primary sector recovery policy. Ministry for Primary Industries, Wellington, New Zealand. [online] URL: https://www.mpi.govt. nz/dmsdocument/14623/direct

Ministry for Primary Industries. 2019a. What is Mycoplasma bovis? Ministry for Primary Industries, Wellington, New Zealand. [online] URL: https://www.biosecurity.govt.nz/protection-andresponse/mycoplasma-bovis/what-is-mycoplasma-bovis/

Ministry for Primary Industries. 2019b. Technical Advisory Group Mycoplasma bovis 2017: review of response progress and recommendations. Ministry for Primary Industries, Wellington, New Zealand. [online] URL: https://www.biosecurity.govt.nz/ dmsdocument/32914/direct

Ministry for Primary Industries. 2019c. How eradication works on infected farms. Ministry for Primary Industries, Wellington, New Zealand. [online] URL: https://www.biosecurity.govt.nz/ protection-and-response/mycoplasma-bovis/advice-for-farmers-undercontrols/how/

Ministry of Civil Defence \& Emergency Management. 2019. National disaster resilience strategy. Ministry of Civil Defence \& Emergency Management, Wellington, New Zealand. [online] URL: https://www.civildefence.govt.nz/cdem-sector/plans-andstrategies/national-disaster-resilience-strategy/

Mol, A., A. Tait, and G. Macara. 2017. An automated drought monitoring system for New Zealand. Weather and Climate 37 (1):23-36. https://doi.org/10.2307/26735444

Morrissey, S. 2018. The start of a conversation on the value of New Zealand's human capital. New Zealand Treasury, Wellington, New Zealand. [online] URL:_https://treasury.govt. nz/sites/default/files/2018-02/dp18-02.pdf

Morse, S., and N. McNamara. 2013. Sustainable livelihood approach: a critique of theory and practice. Springer, Dordrecht, The Netherlands.

Naess, L. O. 2013. The role of local knowledge in adaptation to climate change: role of local knowledge in adaptation. WIREs Climate Change 4:99-106. https://doi.org/10.1002/wcc.204
Nalau, J., and J. Handmer. 2015. When is transformation a viable policy alternative? Environmental Science \& Policy 54:349-356. https://doi.org/10.1016/j.envsci.2015.07.022

New Zealand Treasury. 2018. The Treasury approach to the living standards framework. New Zealand Treasury, Wellington, New Zealand. [online] URL: https://treasury.govt.nz/sites/default/ files/2018-02/tp-approach-to-lsf.pdf

New Zealand Treasury. 2019. Our living standards framework. New Zealand Treasury, Wellington, New Zealand. [online] URL: https://treasury.govt.nz/information-and-services/nz-economy/higherliving-standards/our-living-standards-framework

Ocampo, J. A., and N. Gómez-Arteaga. 2016. Accountability in international governance and the 2030 Development Agenda. Global Policy 7(3):305-314. https://doi.org/10.1111/1758-5899.12322

Olsson, L., A. Jerneck, H. Thoren, J. Persson, and D. O’Byrne. 2015. Why resilience is unappealing to social science: theoretical and empirical investigations of the scientific use of resilience. Science Advances 1(4):e1400217. https://doi.org/10.1126/sciadv.1400217

Ostadtaghizadeh, A., A. Ardalan, D. Paton, H. Jabbari, and H. R. Khankeh. 2015. Community disaster resilience: a systematic review on assessment models and tools. PLoS Currents Disasters 7. https://doi.org/10.1371/currents.dis.f224ef8efbdfcf1d508dd0de4d8210ed

Paton, D., and D. Johnston. 2001. Disasters and communities: vulnerability, resilience and preparedness. Disaster Prevention and Management 10(4):270-227. https://doi.org/10.1108/ EUM0000000005930

Pimm, S. L., I. Donohue, J. M. Montoya, and M. Loreau. 2019. Measuring resilience is essential to understand it. Nature Sustainability 2(10):895-897. https://doi.org/10.1038/s41893-019-0399-7

Potter, S. H., J. S. Becker, D. M. Johnston, and K. P. Rossiter. 2015. An overview of the impacts of the 2010-2011 Canterbury earthquakes. International Journal of Disaster Risk Reduction 14:6-14. https://doi.org/10.1016/j.ijdrr.2015.01.014

Putnam, R. 2000. Bowling alone: the collapse and revival of American community. Simon \& Schuster, New York, New York, USA.

Salomon, A. K., A. E. Quinlan, G. H. Pang, D. K. Okamoto, and L. Vazquez-Vera. 2019. Measuring social-ecological resilience reveals opportunities for transforming environmental governance. Ecology and Society 24(3):16. https://doi.org/10.5751/ES-11044-240316

Scrivens, K., and C. Smith. 2013. Four interpretations of social capital: an agenda for measurement. OECD Statistics Working Papers, No. 2013/06. OECD, Paris, France. https://doi. org/10.1787/5jzbcx010wmt-en

Shields, G. S., M. A. Sazma, and A. P. Yonelinas. 2016. The effects of acute stress on core executive functions: a meta-analysis and comparison with cortisol. Neuroscience and Biobehavioral Reviews 68:651-668. https://doi.org/10.1016/j.neubiorev.2016.06.038

Spector, S., N. A. Cradock-Henry, S. Beaven, and C. Orchiston. 2019. Characterising rural resilience in Aotearoa-New Zealand: 
a systematic review. Regional Environmental Change 19 (2):543-557. https://doi.org/10.1007/s10113-018-1418-3

Stevenson, J., J. Becker, N. Cradock-Henry, S. Johal, D. Johnston, C. Orchiston, and E. Seville. 2017. Economic and social reconnaissance: Kaikoura earthquake 2016. Bulletin of the New Zealand Society for Earthquake Engineering 50(2):343-351. https://doi.org/10.5459/bnzsee.50.2.343-351

Stiglitz, J. E., J.-P. Fitoussi, and M. Durand. 2018. Beyond GDP: measuring what counts for economic and social performance. OECD, Paris, France. https://doi.org/10.1787/9789264307292-en

Strathern, M. 1997. 'Improving ratings': audit in the British University system. European Review. John Wiley \& Sons 5 (3):305-321. https://doi.org/10.1002/(sici)1234-981x(199707)5:3<305:: aid-euro $184>3.0 . c 0 ; 2-4$

Sword-Daniels, V., C. Eriksen, E. E. Hudson-Doyle, R. Alaniz, C. Adler, T. Schenk, and S. Vallance. 2016. Embodied uncertainty: living with complexity and natural hazards. Journal of Risk Research 21(3):290-307. https://doi.org/10.1080/13669877.2016.1200659

Tanner, T., D. Lewis, D. Wrathall, R. Bronen, N. Cradock-Henry, S. Huq, C. Lawless, R. Nawrotzki, V. Prasad, M. A. Rahman, R. Alaniz, K. King, K. McNamara, M. Nadiruzzaman, S. HenlyShepard, and F. Thomalla. 2015. Livelihood resilience in the face of climate change. Nature Climate Change 5(1):23-26. https://doi. org/10.1038/nclimate2431

Taubenböck, H., and C. Geiß. 2014. Vulnerability and resilience research: a critical perspective. International Journal of Disaster Risk Science 5(1):86-87. https://doi.org/10.1007/s13753-014-0011-8

Templeton, H. 1995. All honourable men: inside the Muldoon Cabinet. Auckland University Press, Auckland, New Zealand.

Trotter, M. J., and V. Ivory. 2019. A systems-based framework as an engagement tool: adaptation for insight on transport network resilience. Case Studies on Transport Policy 7(2):167-177. https:// doi.org/10.1016/j.cstp.2019.03.007

Turner, B. L. 2010. Vulnerability and resilience: coalescing or paralleling approaches for sustainability science? Global Environmental Change 20(4):570-576. https://doi.org/10.1016/j. gloenvcha.2010.07.003

Ungar, M. 2008. Resilience across cultures. British Journal of Social Work 38(2):218-235. https://doi.org/10.1093/bjsw/bcl343

Ungar, M. 2011. The social ecology of resilience: addressing contextual and cultural ambiguity of a nascent construct. American Journal of Orthopsychiatry 81(1):1-17. https://doi. org/10.1111/j.1939-0025.2010.01067.x

Ungar, M. 2018. Systemic resilience: principles and processes for a science of change in contexts of adversity. Ecology and Society 23(4):34. https://doi.org/10.5751/ES-10385-230434

United Nations Office for Disaster Risk Reduction (UNISDR). 2015. Sendai framework for disaster risk reduction 2015-2030. UNISDR, Geneva, Switzerland.
Vallance, S. 2015. Disaster recovery as participation: lessons from the Shaky Isles. Natural Hazards 75:1287-1301. https://doi. org/10.1007/s11069-014-1361-7

Vitalis, V. 2007. Agricultural subsidy reform and its implications for sustainable development: the New Zealand experience. Environmental Sciences 4(1):21-40. https://doi.org/10.1080/156$\underline{93430601108086}$

Walker, B. H., L. H. Gunderson, A. P. Kinzig, C. Folke, S. R. Carpenter, and L. Schultz. 2006. A handful of heuristics and some propositions for understanding resilience in social-ecological systems. Ecology and Society 11(1):13. https://doi.org/10.5751/ ES-01530-110113

Woolcock, M. 2001. The place of social capital in understanding social and economic outcomes. Canadian Journal of Policy Research 2(1):11-17

Young, G., H. Zavala, J. Wandel, B. Smit, S. Salas, E. Jimenez, M. Fiebig, R. Espinoza, H. Diaz, and J. Cepeda. 2010. Vulnerability and adaptation in a dryland community of the Elqui Valley, Chile. Climatic Change 98:245-276. https://doi. org/10.1007/s10584-009-9665-4

Zaidi, R. Z. 2018. Beyond the Sendai indicators: application of a cascading risk lens for the improvement of loss data indicators for slow-onset hazards and small-scale disasters. International Journal of Disaster Risk Reduction 30:306-314. https://doi. org/10.1016/j.ijdrr.2018.03.022

Zhao, Y., J. Fan, B. Liang, and L. Zhang. 2019. Evaluation of sustainable livelihoods in the context of disaster vulnerability: a case study of Shenzha County in Tibet, China. Sustainability 11 (10):2874. https://doi.org/10.3390/su11102874 